\title{
HEC-HMS Model for Runoff Simulation in a Tropical Catchment with Intra-Basin Diversions - Case Study of the Deduru Oya River Basin, Sri Lanka
}

\author{
D. S. Sampath, S. B. Weerakoon and S. Herath
}

\begin{abstract}
Hydrological modeling is a commonly used tool by water resource planners to simulate the hydrological response in a basin due to precipitation for the purpose of management of basin water. With the increasing demand for limited water resources in every basin, careful management of water resources becomes more important. The Deduru Oya river in Sri Lanka supplies water to number of new and ancient irrigation systems and the management of water resources in the Deduru Oya river basin, which has an area of $2620 \mathrm{~km}^{2}$, is important for optimum utilization of water for these irrigation systems. This paper describes a case study of continuous rainfall-runoff modeling in part of the Deduru Oya basin with intra-basin diversions and storage irrigation systems using the Hydrologic Engineering Center - Hydrologic Modeling System (HEC-HMS) version 3.0.1 to estimate runoff in the Deduru Oya river.
\end{abstract}

Long term daily rainfall data at several rain gauging stations, evaporation, land use and soil data in the river basin, daily river runoff at a stream gauging station, intra-basin diversions from the river into a storage reservoir, irrigation releases from the reservoir and drainage flow returned to the river from irrigation systems were used to set up the HEC-HMS model. Five-layer soil moisture accounting loss method, Clark unit hydrograph transformation method, and recession base flow method of the HECHMS model were used. Temporally varying irrigation water uses, storages and losses in the basin were taken into account in the analysis. The results depict the capability of HEC-HMS to reproduce stream flows in the basin to a high accuracy with averaged computed Nash Sutcliffe efficiencies of 0.80. The study demonstrates potential HEC-HMS application in flow estimation from tropical catchments with intra-basin diversions and irrigation storages. The model developed is a tool for water management in the Deduru Oya river basin.

Keywords: Deduru Oya basin, HEC-HMS, Hydrological Modeling, Irrigation, Magalla tank

\section{Introduction}

Sustainable management of limited fresh water sources is a major challenge and is extremely important for the people living in the world. Failure to manage the water sources in an effective manner will adversely affect the society and the economy of the country. Management of water resources in a basin essentially requires understanding of dynamics of basin water and assessment of basin water availability for development use.

Hydrological modeling is a commonly used tool to estimate the basin's hydrological response due to precipitation. Various types of hydrological models from black box models which require less basin data to physically based models which require large amount of basin data have been developed [2]. The selection of the model depends on the basin and the objective of the hydrological prediction in the basin.

The HEC-HMS, developed by Hydrologic Engineering Center of U.S. Army Corps of Engineers is a hydrological model that supports both lumped parameter based modeling as well as distributed parameter based modeling [15]. HEC-HMS is a set of mathematical models to simulate the precipitation runoff-routing processes of dendritic watershed system.

\footnotetext{
Eng. D. S. Sampath, B. Sc. Eng.(Hons)(Peradeniya), AMIE(Sri Lanka), Lecturer (Probationary), Dept. of Civil Engineering, University of Jaffna, Ariviyal Nagar, Kilinochchi, Sri Lanka and M. Phil. candidate, Dept. of Civil Engineering, University of Peradeniya, Peradeniya, Sri Lanka.

Eng. (Prof.) S. B. Weerakoon, B.Sc.Eng.(Peradeniya), M.Eng., D.Eng. (Tokyo), FIE(Sri Lanka), Int. PE SL, C. Eng, Professor of Civil Engineering, Dept. of Civil Engineering, University of Peradeniya, Peradeniya, Sri Lanka.

Prof. Srikantha Herath, B.Sc.Eng.(Peradeniya), M.Eng. (AIT), D.Eng. (Tokyo), Senior Academic Programme Director, UNU-IAS, Tokyo, Japan.
} 


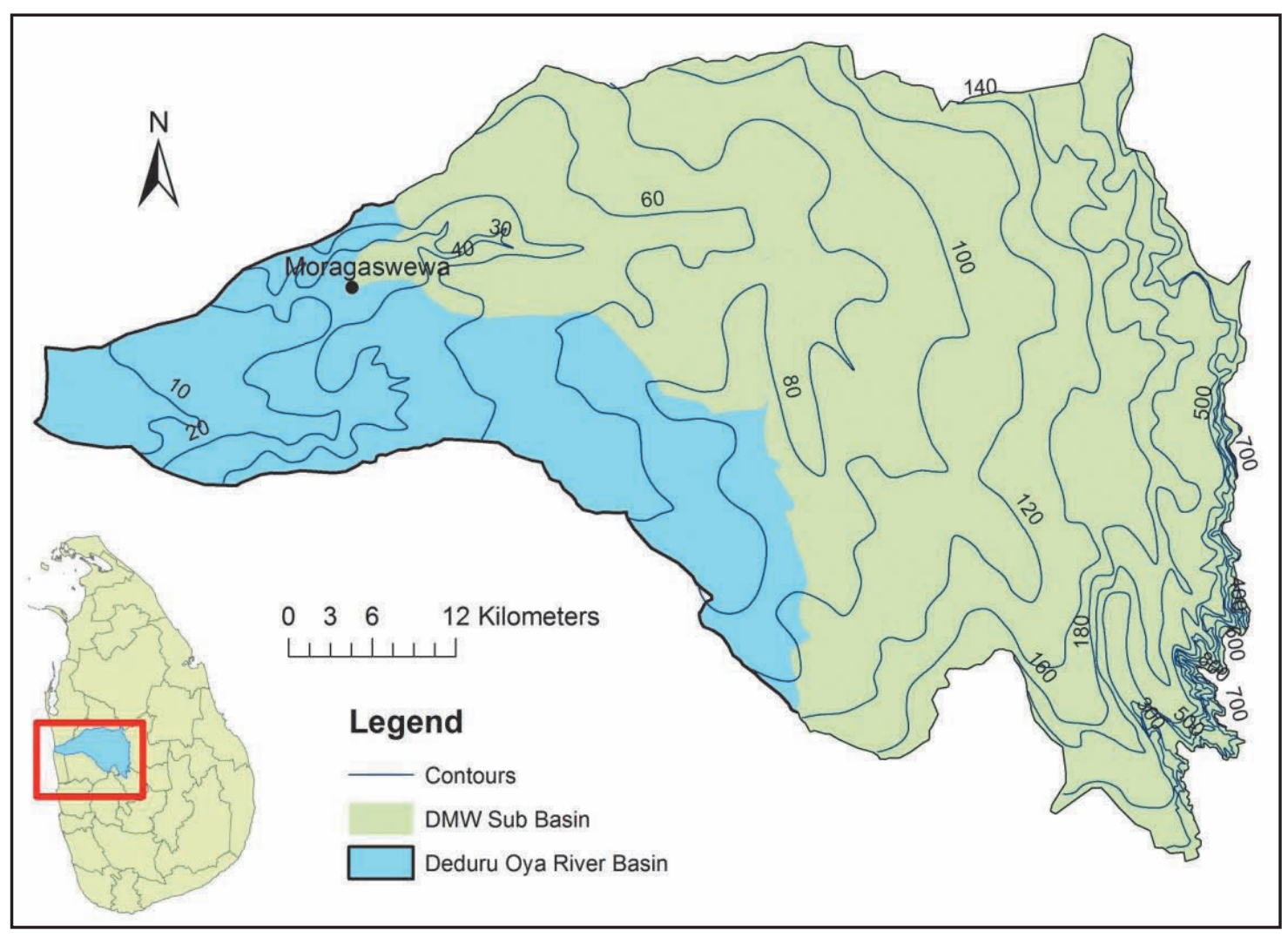

Figure 1 - Location and Topography of the Basin

HEC-HMS needs three input components such as the basin model, the meteorological model, and the control specifications. The basin model is the representation of real-world objects with parameters describing their behavior. The basin model elements are sub basin, reach, junction, source, sink, reservoir, diversion, river reach, point of intersection of river reaches, input flow point to basin system, outlet of the basin system, reservoir, and diversion for a reach in the real world, respectively. Each of these elements needs some parameters to define their behavior in a hydrologic system. Each element stores the element downstream to it to facilitate the flow of water and to create a dendritic network [1].

The metrological model is responsible for preparing the boundary conditions that act on the watershed during a simulation. The meteorological model stores the information of precipitation falling on the watershed and evapotranspiration. HEC-HMS supports six different historical and synthetic precipitation methods as well as one evapotranspiration method [15].

The time span of a simulation is controlled by control specifications and control specification is used to describe the time period and time step for simulation. Control specifications include a starting date and time, ending date and time, and a time interval [15]. The input time-series and other paired-value data are stored in HEC's Data Storage System (DSS). The output of HEC-HMS includes peak flow and total volume for each element in the basin model. These output data are also stored in DSS [1].

HEC-HMS has been successfully applied to many basins to assess water resources including river basins in Sri Lanka [(4), (8)]. In this paper the HEC HMS Model is applied for a part of the Deduru Oya river basin (Deduru Oya river basin above Moragaswewa $\left(79.990^{\circ} \mathrm{E}\right.$, $7.700^{\circ} \mathrm{N}$ ) hereafter referred as DMW sub basin) in Sri Lanka which is a special case of practical importance where there are intra-basin diversions for irrigation systems. Irrigation systems release part of irrigated water as drainage flow to the downstream of them and these drainage flows enter into the basin drainage network and contributes to the flow at the downstream reach of the Deduru Oya river in the DMW sub basin. HEC-HMS model is used for rainfall-runoff modeling of DMW sub basin which contains intra-basin diversions and storages. 


\section{1}

\section{DMW sub basin of Deduru Oya River} basin

DMW sub basin, which is an upper basin of the Deduru Oya river, has an area of $1950 \mathrm{~km}^{2}$ ranging from $30 \mathrm{~m}$ to $1280 \mathrm{~m}$ MSL extending from Moragaswewa to the central hills of Sri Lanka (Figure 1). DMW sub basin of Deduru Oya river basin covers $74 \%$ of whole Deduru Oya river basin. DMW sub basin, located between $7.320^{\circ} \mathrm{N}$ and $7.860^{\circ} \mathrm{N}$ latitudes, and $79.990^{\circ} \mathrm{E}$ and $80.580^{\circ} \mathrm{E}$ longitudes, is one of the major rice production basins in the country. The Deduru Oya river of DMW sub basin flows through Matale and Kurunegala districts.

The basin contains a number of small and large reservoirs (tanks), mostly rain-fed, used for irrigating paddy cultivation in two seasons per year. There are several weirs (anicuts) built across the river along its length to divert water for irrigation system to cultivate paddy. There are few reservoirs across tributaries of Deduru Oya river but the only reservoir intercepting the Deduru Oya river is the one being constructed under ongoing Deduru Oya reservoir project.

Rainfall is the only source of water and there are no transbasin diversions into or out of the basin at present. The rainfall in the basin has a significant temporal and spatial variation. Annual rainfall ranges from $2600 \mathrm{~mm}$ in the upper basin to $1100 \mathrm{~mm}$ in the lower basin. From the annual rainfall about $50 \%$ is received during inter monsoon months (March-April \& October-November), about 35\% during Southwest monsoon months (May to September), and remaining $15 \%$ during Northeast monsoon months (December to February). The Deduru Oya river carries flash floods during rainy season and very low flow during dry season. Presently nearly 1000 MCM of water flows to sea annually from Deduru Oya river basin without being used in the basin [13]. There is a strong need to store flood water carried by Deduru Oya river to use during lean season, especially for irrigation.

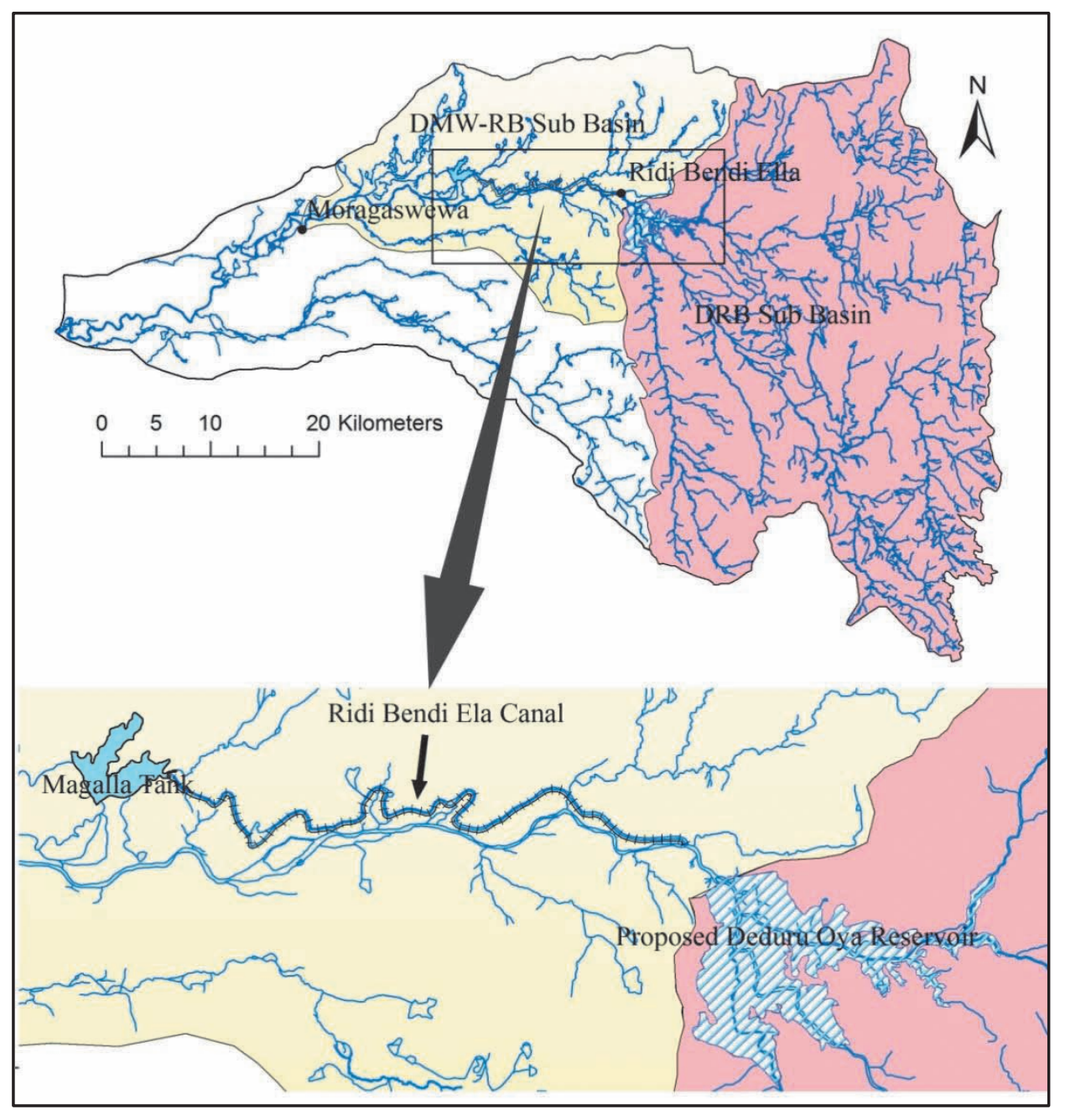

Figure 2 - Study Area 


\subsection{Intra-basin diversion to Magalla tank}

There is an intra-basin diversion of considerable volume of the Deduru Oya river flow to the right bank at its middle reach for irrigated paddy cultivation. A weir constructed across the river diverts water to an unlined canal (Ridi Bendi Ela canal) of $21 \mathrm{~km}$ length and $4.25 \mathrm{~m}^{3} / \mathrm{s}$ capacity to Magalla tank (Figure 2). The weir diverts almost all of the flow of the river to the Magalla tank during low river flow months. The Magalla tank with a capacity of 9 MCM stores water for the irrigation requirements in downstream areas. The basin area of Magalla tank is $32 \mathrm{~km}^{2}$. There are 2224 ha of paddy lands cultivated presently under the Magalla tank irrigation system.

The Magalla tank has three irrigation canals; Right Bank (RB) canal, Left Bank (LB) canal and Centre canal to distribute water. Capacities of the canals and the irrigable areas under each canal are shown in Table 1. The drainage water from the paddy fields at Magalla tank irrigation systems flows into the Deduru Oya river at the upstream of Moragaswewa (Figure 2).

Table 1 - Capacities of Magalla Tank Outlet Canals and Irrigation Area

\begin{tabular}{|l|l|c|}
\hline \multicolumn{1}{|c|}{ Canal } & Capacity & $\begin{array}{c}\text { Irrigation } \\
\text { Area }\end{array}$ \\
\hline RB Canal & $3.40 \mathrm{~m}^{3} / \mathrm{s}$ & $1792 \mathrm{ha}$ \\
\hline LB Canal & $1.13 \mathrm{~m}^{3} / \mathrm{s}$ & $312 \mathrm{ha}$ \\
\hline Center Canal & $0.43 \mathrm{~m}^{3} / \mathrm{s}$ & $120 \mathrm{ha}$ \\
\hline
\end{tabular}

\section{Methodology}

For the application of HEC-HMS, the DMW sub basin which has an area of $1950 \mathrm{~km}^{2}$ was divided into two sub-basins; DRB sub basin of an area of $1400 \mathrm{~km}^{2}$ above the irrigation diversion at Ridi Bendi Ela and rest of the DMW basin (referred to as DMW-RB sub basin) of an area of $550 \mathrm{~km}^{2}$ (Figure 2). The schematic diagram of the HEC-HMS model setup is given in Figure 3.

Ridi Bendi Ela canal was modeled as a diversion element and Magalla tank was modeled as a reservoir element. The drainage flow from the irrigation systems under Magalla tank is modeled as a reach element.

Daily stream flow at the DRB basin outlet was estimated by HEC-HMS model application to the DRB basin. Diversion to Magalla reservoir

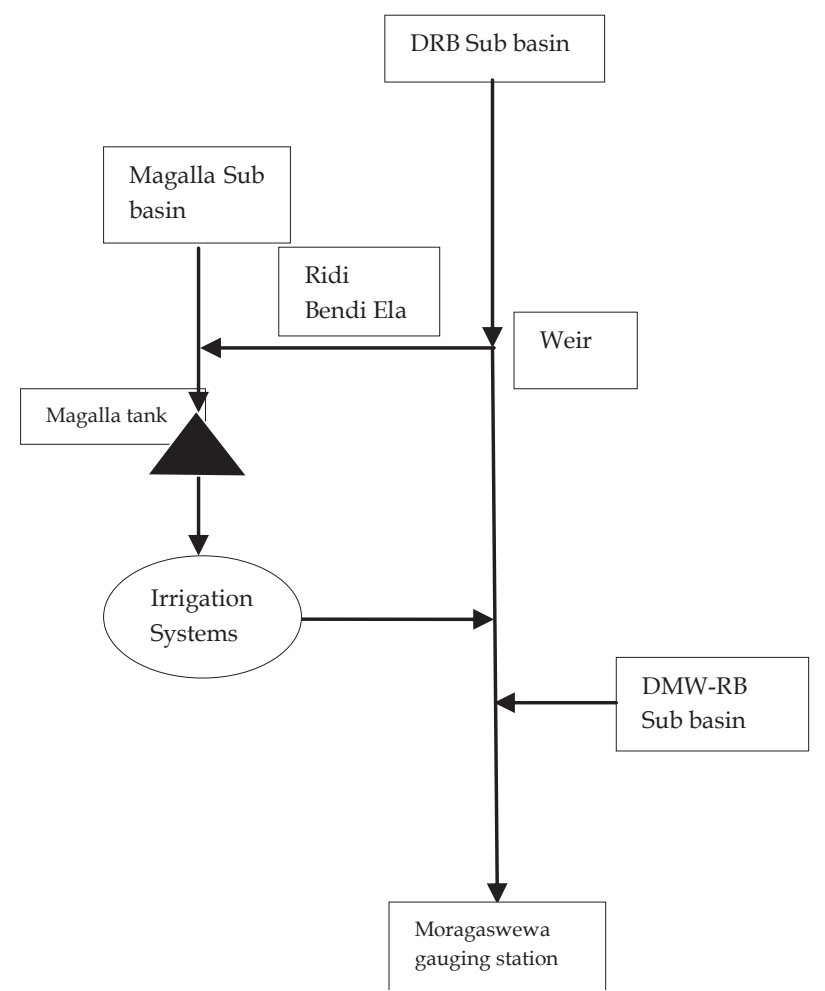

Figure 3 - Schematic Diagram

from DRB basin outlet through Ridi Bendi Ela canal is $4.25 \mathrm{~m}^{3} / \mathrm{s}$ or maximum available at the DRB basin outlet. The flow in excess of 4.25 $\mathrm{m}^{3} / \mathrm{s}$ is an inflow to the DMW-RB basin through Deduru Oya river.

Magalla tank receives inflow from its own basin and from the Ridi Bendi Ela canal. Daily releases from Magalla reservoir for irrigation systems through the three canals depend on the irrigation requirements and available storage.

Reservoir simulation was carried out to estimate the actual daily releases.

Irrigation requirements in the irrigation systems were estimated by CROPWAT model. Drainage flow from the irrigation systems was taken as $40 \%$ of the total release of Magalla tank through the three canals according to loss calculation and water balance study.

\subsection{Data collection}

GIS data were used to identify stream paths, catchments, natural streams, land use patterns, geology and soil types in the basin. Topographic, geological and land use details were collected from the digital data of the Survey Department of Sri Lanka. A major portion of the soil in river basin was identified as reddish brown earth [(9), (11)]. 
Daily rainfall was collected from seven stations in the basin (Figure 4), viz. Kurunegala, Delwita, Wariyapola, Millawa, Ridi Bendi Ela, Batalagoda and Nikaweratiya, for the past twenty years from 1980 to 2000. Monthly evaporation data for the same years for the agro meteorological station Mahawa was used in the study. The rainfall data and the evaporation data were obtained from the Rainfall Division of the Department of Meteorology, Colombo. Also hydro meteorological data are available at the Department of Meteorology [10]. The only flow data available for the Deduru Oya is from 1980 to 1989 at Moragswewa gauging station. Daily flow data for the latest three year from this data set was used for model calibration and validation, viz. 3 months for calibration and 3 years for validation.
For the calculation of CWRs, CROPWAT needs data on evapotranspiration (ETo), rainfall, crop data and soil data. CROPWAT allows the user to either enter measured ETo values, or to input data on temperature, humidity, wind speed and sunshine, which allows CROPWAT to calculate ETo using the Penman-Monteith formulae [3].

Rainfall data are used with CROPWAT to compute effective rainfall data as input for the CWR and scheduling calculations. Crop data are needed for the CWR calculations and soil data to calculate irrigation schedules. Whereas CROPWAT normally calculates CWR and schedules for one crop, it can also calculate a scheme supply, which is basically the combined CWR of multiple crops, each with its individual planting date [3].

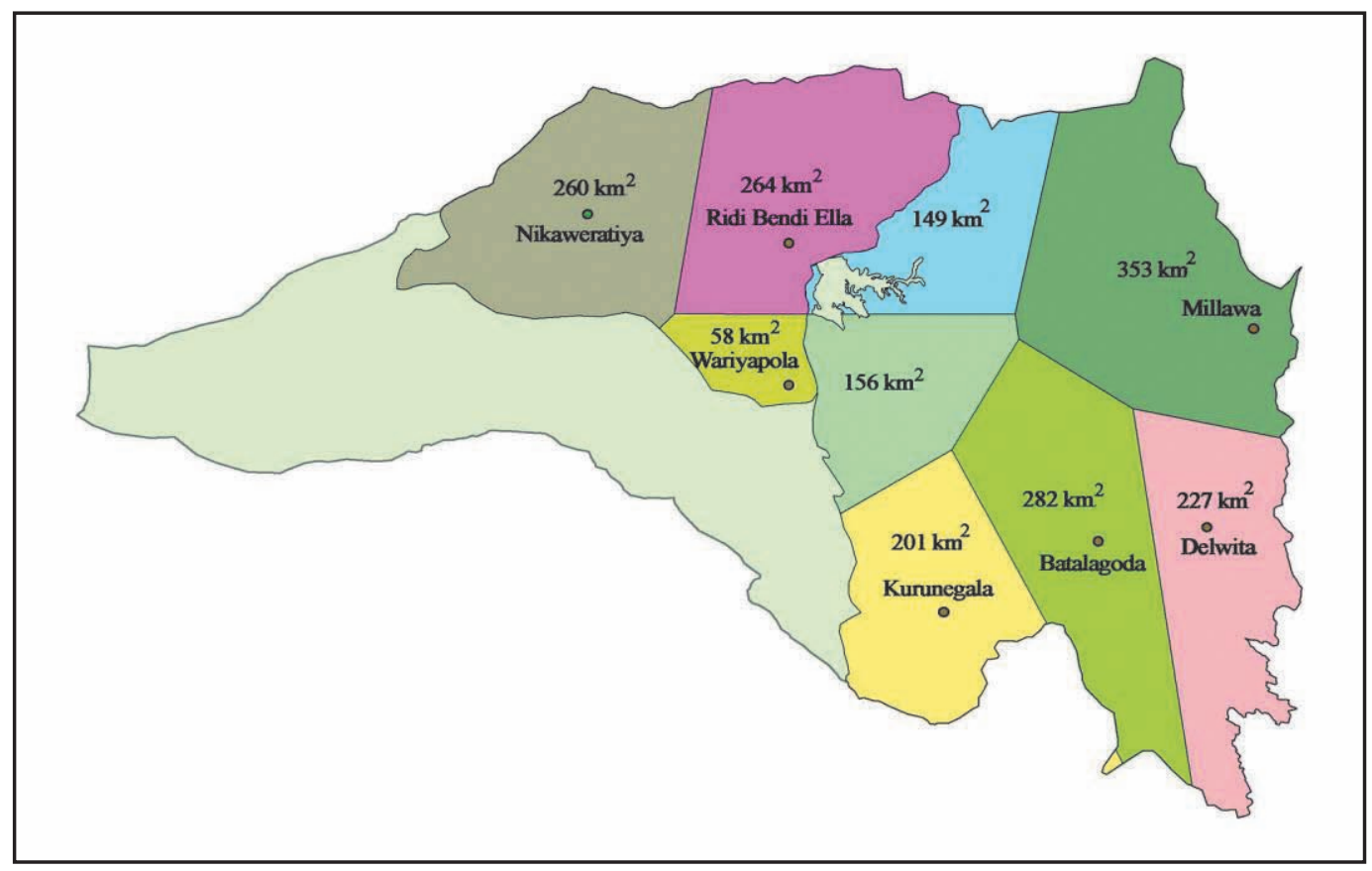

Figure 4 - Rain Gauge Stations and Thiesson Polygon Areas

\subsection{Crop Water Requirements}

CROPWAT 8.0 software developed based on the Food and Agriculture Organization of the United Nations (FAO) guidelines is used for calculation of Crop Water Requirements (CWR) and irrigation requirements from climatic and crop data. The program also allows the development of irrigation schedules for different management conditions and the calculation of scheme water supply for varying crop patterns [(3), (14)]. calculated for 105 day low land paddy crop type. It was calculated using CROPWAT for paddy crop on monthly basis. Rainfall data at Nikaweratiya station in year 1980 to 2000, Mahailuppallama reference crop evapotranspiration rates and crop factors for each growth stages were used for the CROPWAT model to calculate CWR. Computations of irrigation water requirements were made using $60 \%$ application efficiency and $75 \%$ conveyance efficiency. 


\subsection{Model calibration}

HEC-HMS version 3.0.1 was utilized as the rainfall - runoff model in Deduru Oya river basin. Calibration for continuous modeling was carried out by using daily rainfall occurred from Oct 1985 to Dec 1985. Soil moisture accounting loss method, Clark unit hydrograph transformation method, and recession base flow method were utilized for continuous simulations.

The soil moisture accounting loss method uses five layers to represent the dynamics of water movement above and in the soil. Layers include canopy interception, surface depression storage, soil, upper groundwater, and lower groundwater. The soil layer is subdivided into tension storage and gravity storage [(15), (16)]. The soil moisture accounting loss method was utilized for continuous simulations in all sub basins.

Clark unit hydrograph was selected as a transform method. Time of concentration and storage coefficient are the parameters to be defined in Clark unit hydrograph transformation. The time of concentration defines the maximum travel time in the sub basin. It is used in the development of the translation hydrograph. The storage coefficient is used in the linear reservoir that accounts for storage affects [(15), (16)].

The recession base flow method is designed to approximate the typical behavior observed in watersheds when the channel flow recedes exponentially after an event. The initial base flow at the beginning of a simulation must be specified. Two methods are available for specifying the initial condition: initial discharge and initial discharge per area [15]. Here initial discharge was selected as one parameter. The other parameter, recession constant, describes the rate at which base flow recedes between storm events. It is defined as the ratio of base flow at the current time, to the base flow one day earlier. There are two different methods for determining how to reset the base flow during a storm event: ratio to peak and threshold flow [15]. Ratio to peak was selected as a parameter in this study after several trials.

The Muskingum routing method uses a simple conservation of mass approach to route flow through the stream reach. However, it does not assume that the water surface is level. By assuming a linear, but non-level, water surface it is possible to account for increased storage during the rising side of a flood wave and decreased storage during the falling side. The Muskingum $\mathrm{K}$ is essentially the travel time through the reach. It can be estimated from the knowledge of the cross section properties and flow properties. The Muskingum $X$ is the weighting between inflow and outflow influence [15].

The inflow-diversion function defines the amount of flow that is diverted from a given inflow. Inflow is the independent variable. The range of inflows specified in the function should cover the complete range of total inflows from upstream elements. The inflowdiversion function must be defined in the paired data manager before it can be used in the diversion elements [15].

Normalized Objective Function (NOF), Nash Sutcliffe efficiency $\left(R_{N S}^{2}\right)$, Percentage bias $\left(\delta_{b}\right)$ and Root Mean Square Error (RMSE) values were used as quantitative measures for the skill of simulations. Past studies have shown that these parameters were successfully used to analyze goodness of fit [(5), (6), (12)].

$$
\begin{gathered}
N O F=\frac{1}{\bar{O}} \sqrt{\frac{1}{n} \sum_{i=1}^{n}\left(O_{i}-S_{i}\right)^{2}} \\
R_{N S}^{2}=1-\frac{\sum_{i=1}^{n}\left(S_{i}-O_{i}\right)^{2}}{\sum_{i=1}^{n}\left(O_{i}-\bar{O}\right)^{2}} \\
\delta_{b}=\left|\frac{\sum_{i=1}^{n}\left(S_{i}-O_{i}\right)}{\sum_{i-1}^{n} O_{i}}\right| * 100 \% \\
R M S E=\sqrt{\frac{1}{T} \sum_{i=1}^{n}\left(O_{i}-S_{i}\right)^{2}}
\end{gathered}
$$

Where, $O_{i} S_{i} n \bar{O}$ are observed discharge, simulated discharge, number of the observed or simulated data points and mean of the observed discharge respectively.

All calibration and validation graphical representations were numerically analyzed by the goodness of fit according to Normalized Objective Function (NOF), Nash-Sutcliffe efficiency $\left(R_{N S}^{2}\right)$, percentage bias $\left(\delta_{b}\right)$ and Root Mean Square Error ( $R M S E)$ values. 
If the simulated values exactly match with the observed, NOF, $R_{N S}^{2}, \delta_{b}$ and $R M S E_{\text {would }}$ be equals to zero, one, zero percent and zero respectively.

\section{Results and Discussions}

\subsection{Calibration}

For the calibration period, which is from Oct Dec 1985, simulated daily discharge values were compared with observed daily discharge values. Figure 5 shows the graphical distribution of simulated discharge against observed discharge. The values of $O F, R_{N S}^{2}, \delta_{b}$ and $R M S E$ are equal to $0.30,0.96,4.88 \%$ and 22 respectively.

\subsection{Validation}

The time series data from Oct 1984 to 30 Sept 1985 (1 year) and Oct 1987 to Sept 1989 (2 years) were used for validation of continuous simulation. Validation results indicate that

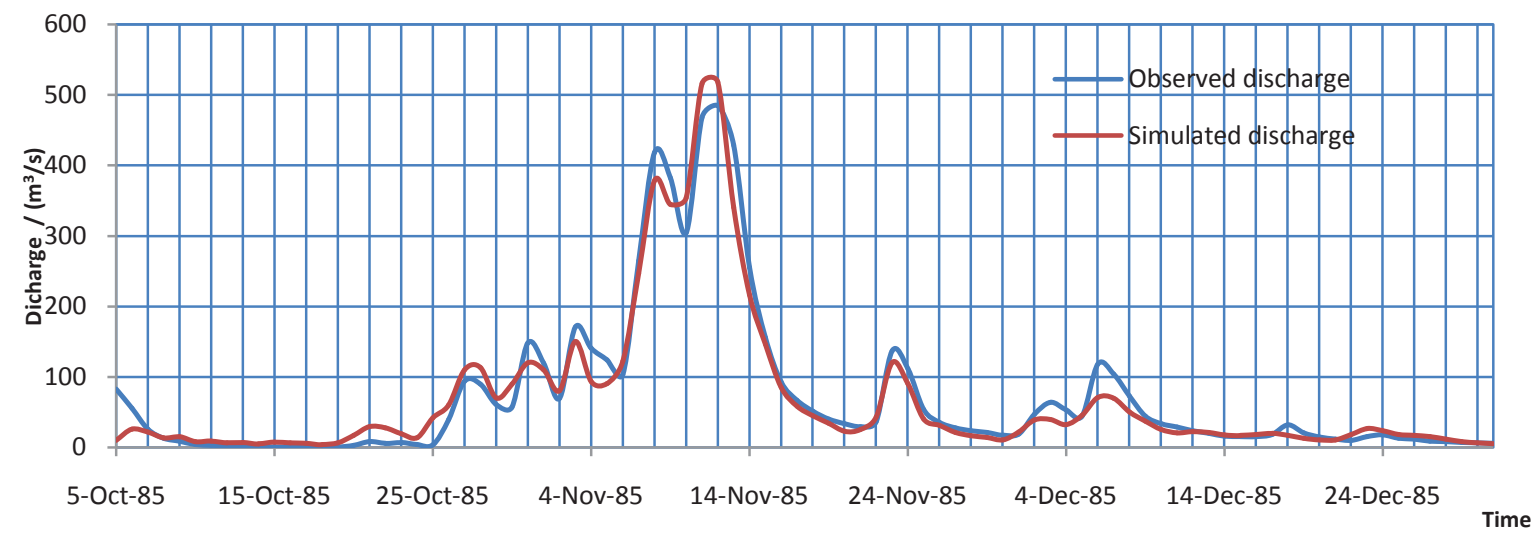

Figure 5 - Observed and Simulated Discharges at Moragaswewa for Oct - Dec 1985

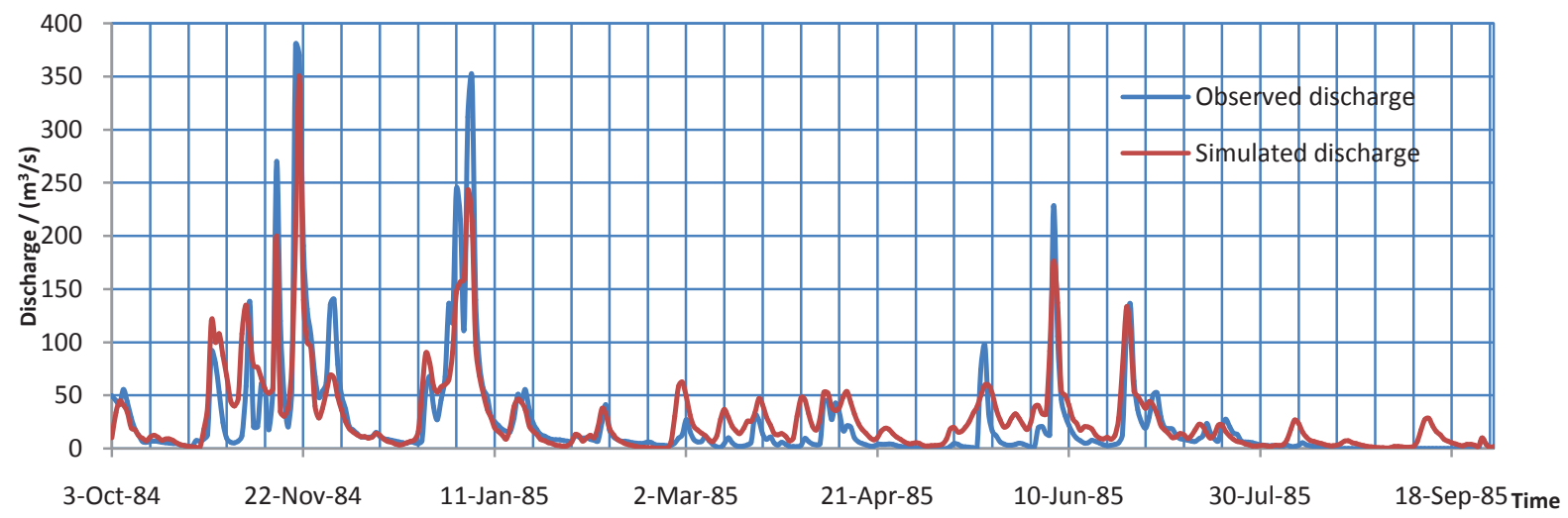

Figure 6 - Observed and Simulated Discharges at Moragaswewa for Oct 1984 - Sept 1985

there is a good agreement between the observed and simulated flows. Table 2 shows the goodness of fitting between simulated and observed flow for validation periods, and the parameters fall within acceptable ranges. The observed and simulated discharge hydrographs are shown in Figure 6 and Figure 7 respectively.

Table 2 - Goodness of Fit for Stream Flow Simulation

\begin{tabular}{|c|c|c|c|c|}
\hline Event & NOF & $\boldsymbol{R}_{\boldsymbol{N} \boldsymbol{S}}^{2}$ & $\boldsymbol{\delta}_{\boldsymbol{b}}$ & $\boldsymbol{R M} \boldsymbol{S} \boldsymbol{}$ \\
\hline $\begin{array}{l}\text { Oct 1984 to } \\
\text { Sept 1985 }\end{array}$ & 1.00 & 0.76 & $18 \%$ & 25 \\
\hline $\begin{array}{l}\text { Oct 1987 to } \\
\text { Sept 1989 }\end{array}$ & 1.00 & 0.7 & $17 \%$ & 34 \\
\hline
\end{tabular}




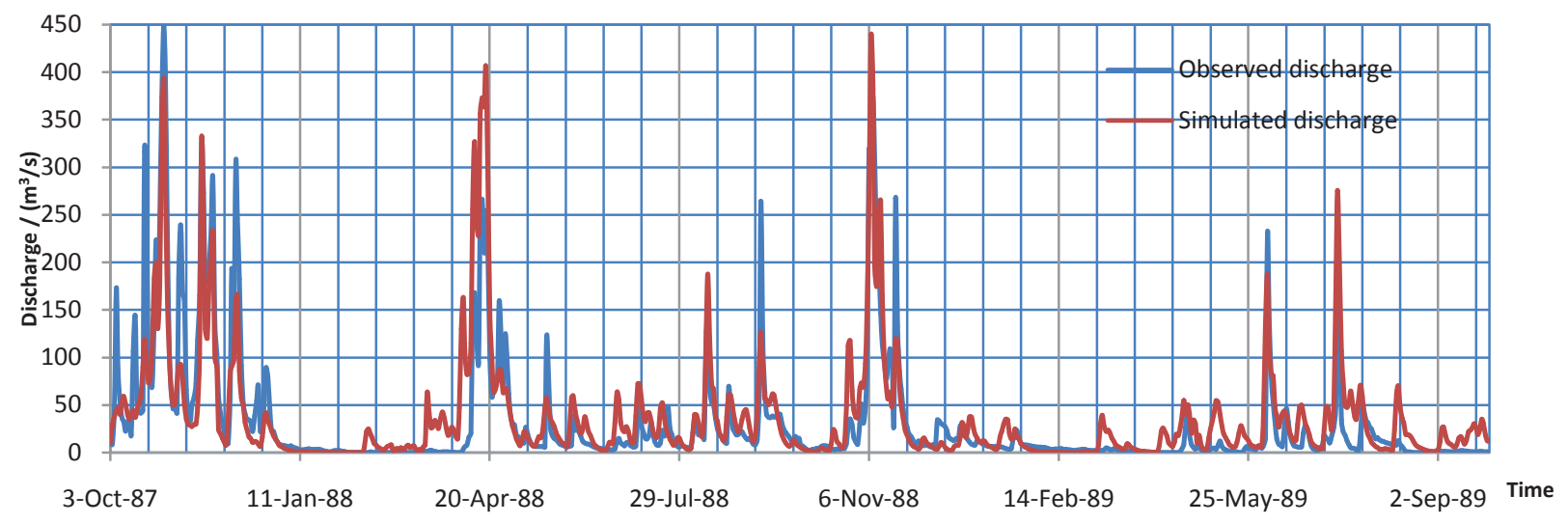

Figure 7 - Observed and Simulated Discharges at Moragaswewa for Oct 1987- Sept 1989

\section{Conclusions}

Paper presented a case study of runoff modeling of part of Deduru Oya river basin with intra- basin diversion and storages by using the HEC-HMS model. The study used the computed skill metrics of simulated stream flow against observation as a criterion to calibrate model parameters. Simulation skills, as described by $N O F, R_{N S}^{2}, \delta_{b}$ and $R M S E$ agree reasonably well against observed discharges.

The results show that the calibrated model is capable of capturing the seasonal characteristics of stream flow satisfactorily. By using long term forecast daily rainfall, the model with the calibrated parameters can be used for estimating stream flow at the basin outlet. The study demonstrates potential HEC-HMS application in flow estimation from tropical catchments with intra-basin diversions and irrigation storages. The model developed is a useful tool for water management in the Deduru Oya river basin.

\section{Acknowledgements}

The authors would like to convey their sincere gratitude to UN-CECAR program of United Nations University, Tokyo, Japan, for the financial support for this research. The hydrological and meteorological data for the study were obtained from the Department of Irrigation and Department of Meteorology.

\section{References}

1. Agrawal, A., "A Data Model with Pre and Post Processor for HEC-HMS", Report of Graduate Studies, Texas A \& M Univ. College Station, 2005.

2. Chong-yu $\mathrm{Xu}$, Text book of Hydrological model, Uppsala university department of earth science and hydrology, 2002.

3. Cropwat Reference Manual, 2009.

4. DE Silva, M. M. G. T., Weerakoon, S. B., Herath S., Modeling of Event and Continuous Flow Hydrographs with HECHMS; A Case Study in the Kelani River basin Sri Lanka, J. of Hydrologic Engineering, ASCE, Vol. 19 No 04, 800-806, 2014.

5. Deva, K., Borah, M., ASCE; Jeffrey, G., Arnold; Maitreyee Bera; Edward, C., Krug; and Xin-Zhong Liang, 2007, Storm Event and Continuous Hydrologic Modeling for Comprehensive and Efficient Watershed Simulations, Journal of Hydrologic Engineering, Vol. 12, No. 6, November 1, 606616.

6. Moriasi, D. N., Arnold, J. G., Van Liew, M. W., Bingner, R. L., Harmel, R. D., Veith, T. L., 2007, Model Evaluation Guidelines for Systematic Quantification of Accuracy in Watershed Simulations, American Society of Agricultural and Biological Engineers, ISSN 0001-2351, Vol. 50(3): 885-900.

7. Ehret, U., and Zehe, E., Series Distance - An Intuitive Metric to Quantify Hydrograph Similarity in Terms of Occurrence, Amplitude and Timing of Hydrological Events ,J. of Hydrology and Earth System Sciences, Vol. 15., 877-896, 2011.

8. Halwatura, D., Najim, M. M. M., "Application of the HEC-HMS Model for Runoff Simulation in a Tropical Catchment, J. of Environmental modeling and software, 46, 155-162, 2013. 
10. Long-term Hydro Meteorological Data in Sri Lanka, Data Book of Hydrological Cycle in Humid Tropical Ecosystem, Part I, Ed. K. Nakagawa, H., Edagawa, V., Nandakumar \& Aoki, M., Special Research Projection 1995, University of Tsukaba.

11. Mapa, R. B., Dissanayake, A. R., Nayakakorale H. B., Soil of the Intermediate Zone of Sri Lanka: Morphology characterization and classification, 2005.

12. Nash, J. E. and Sutcliffe, J. V., "River Flows Forecasting Through Conceptual Models. Part 1 a Discussion of Principles", J. Hydrology, Vol. 27 (3), pp. 282-290, 1970

13. Pre-feasibility Study Report of Deduru Oya and Mee Oya river basins Development Project, Planning Branch, Irrigation Department, Colombo, Sri Lanka, 2000.

14. Richard, G. A., Luis, S. P., Dirk, R., Martin, S., Crop Evapotranspiration-Guidelines for Computing Crop Water Requirements, Publication No. 56 of the Irrigation and Drainage Series of FAO, FAO, Rome, Italy, 1998.

15. Scharffenberg, W. A. and Fleming, M. J., "Hydrologic Modeling System HEC-HMS User's Manual", US Army Corps of Engineers, Institute for Water Resources, Hydrologic Engineering Centre , 2006

16. US army corps of Engineers, Hydrological Engineering Center, HEC-HMS Technical Reference Manual., March 2000. 